\title{
BEST PRACTICE IN GLOBAL NEGOTIATION STRATEGIES FOR LEADERS AND MANAGERS IN THE $21^{\text {ST }}$ CENTURY
}

\author{
John Saee \\ Swinburne University of Technology, Australia \\ E-mail: jsaee@swin.edu.au \\ Received 20 November 2007; accepted 18 September 2008
}

\begin{abstract}
This research article examines various types of negotiations and negotiation styles and best practice in global negotiations, which may be adopted by leaders and entrepreneurs under different conditions and cultural milieus to reach an agreement while conducting business across the globe.
\end{abstract}

Keywords: negotiation, globalisation, global culture and global leader.

\section{Introduction}

There has been a spectacular watershed in the world economy which is largely precipitated by the phenomenon of globalization. In other words, we are moving increasingly further away from a world in which national economies were relatively isolated from each other by barriers to cross-border trade and investment; by distance, time zones and language; and by national differences in government regulation, culture, and business systems. And we are moving toward a world in which national economies are merging into an interdependent global economic system, commonly referred to as globalization (Saee 2005). Consequently, the twenty first century is witnessing a spectacular growth in globalization of trade across national boundaries made possible through the exporting of products and services, offshore operations, strategic alliances/joint ventures, mergers and acquisitions, licensing and distribution agreements. In early 2006, Luxembourg-based steelmaker Arcelor, which had successfully lured Canada's Dofasco away from Germany's ThyssenKrupp the previous year, became itself the acquisition target of
Mittal Steel, an Indian-controlled firm headquartered in the Netherlands. During the same period, U.S.-owned Boeing sold 27 787-Dreamliners to Air India and finalized a supply contract with Japan's Toray for the carbon fiber needed to produce the aircraft. In China, Google Inc. (U.S.) negotiated with government authorities over regulatory conditions for operation of their Internet search engine. These are but a few examples of the millions of international business (IB) negotiations that occurred during early 2006 . These were the headline-grabbers, but less prominent actors also negotiated across borders. All told, the amount of IB negotiation worldwide seems to have exploded in recent years and shows no signs of abating (Weiss 2006). Meanwhile, much of global trade occurring around the world involves face-to-face negotiations amongst entrepreneurs and representatives of firms who are engaged in making business deals, literally on a daily basis. Arguably, successful negotiators display a highly developed intercultural communication competence - an essential criterion to conduct successful negotiation across the globe. International negotiation is very complex and difficult because it involves different laws, regulations, 
standards, business practices and, above all, cultural differences. Most of the difficulties in international negotiations, however, are, due to cultural differences. That is why negotiation today is considered one of the single most important global business skills. The saying: 'When in Rome, do as the Romans do' is an indication of our awareness that to succeed in international negotiation we need to suppress our ethnocentric tendencies. To conclude successfully a business deal, a labor agreement or a government contract with foreigners, who are in most respects different from us, requires a considerable amount of communication skills. To successfully manage such negotiations, business people need to know how to influence and communicate with members of the culture other than their own (Adler and Graham 1989). It is, therefore, important to understand the cross-cultural sensitivities related to negotiation, and appropriate strategies and tactics to suit a particular situation.

\section{Negotiation defined}

Negotiation is conceived as a process in which at least one individual tries to persuade another individual to change his or her ideas or behavior and it often involves one person attempting to get another to sign a particular contract or make a particular decision. Thus negotiation is the process in which at least two partners with different needs and viewpoints need to reach an agreement on matters of mutual interest (Casse 1981: 152).

Meanwhile, Acuff (1993) has defined negotiation as the process of communicating back and forth for the purpose of reaching a joint agreement about differing needs or ideas. Negotiation is a process in which two or more parties exchange goods or services and attempt to agree upon the exchange rate for them. Arising from the foregoing definitions is the question whether the same applies to cross-cultural negotiation, an important issue that this research article is dedicated to exploring in some details.

\subsection{Cross-cultural negotiation defined}

A negotiation becomes cross-cultural when the parties involved belong to different cultures and therefore do not share the same ways of thinking, feeling, and behaving (Casse 1981). Thus, the meaning of the term 'negotiation' and what it connotes can significantly vary from one culture to another. For example, Americans view negotiations as an opportunity to resolve contentious issues, the Japanese, Chinese, and Mexican cultures view negotiations as a vehicle to establish a relationship; resolving problematic issues is never the first goal (Perlmutter and Heenan 1974). All global negotiations are cross-cultural. Some domestic negotiations, in spanning across two or more ethnic groups, are also cross-cultural. Global negotiations contain all of the complexity of domestic negotiation, with the added dimension of cultural diversity (Adler 1997). Cross-cultural negotiations can be very intricate, as each culture, whether it is a high or low context culture, has its own distinctive approach relating to not only the negotiating process but their individual and religious practices, idiosyncrasies and expectations, with each culture cohered to their own norms, values, laws and beliefs, impacting on the outcome of the agreement. Members of different cultures focus on diverse aspects of an agreement, for example, one may focus on the legal side and the other on the personal aspects. In some cultures, documenting the agreement is significant while in others the process and actual implementation is the focal point (Gulbro and Herbig 1995). For example, Americans negotiate a contract, while the Japanese negotiate a personal relationship. This is all due to the differences in cultural values and norms which stems from the dissimilarity in individualistic cultures such as the USA and collectivist cultures, namely, Japan (Mead 1998). Cross-cultural negotiations consume much time of global managers and negotiation is often ranked as one of the most imperative skills for global managers to possess (George et al. 1998). From small firms, export departments and international companies to multinational corporations and politics throughout the world face-to-face negotiation or negotiation via technology is becoming increasingly widespread. Negotiations are undertaken for numerous purposes: international joint ventures, licensing agreements, seller-buyer relationships, mergers and acquisitions, just to name a few. Even domestic companies that are not multinational in their structure must encounter the challenge of globalization (Saee 2005). Global managers spend more than 50 percent of their time negotiating, and this illustrates the importance of cross-cultural negotiation (Adler 1997).

\subsection{Components of negotiation}

In any negotiation, we can identify three components:

- The process;

- The parties; and

- The agreement or the outcome of the negotiation.

Complications in negotiation arise as the two parties may have different objectives. These objectives may be different from what each party requires from the agreement or different in respect that one party even 
may not want an agreement. Another issue leading to complication could be that the intended routes of the two parties to arrive at the objectives might be quite different. The fact that these issues are often compounded in cross-cultural settings makes the process still more convoluted.

\subsection{Types of negotiations}

Based on cultural dimensions, there are essentially two types of negotiations: intracultural and intercultural negotiations (Fatehi 1996). Intracultural negotiations assume similarity in culture and fields of experience among negotiating parties. Based on this assumption, negotiating strategies are devised to influence the other party's position. Much of negotiation skills involve accomplishing three tasks:

- bringing your own perceptions in line with reality;

- ascertaining the other sides perceptions of the proposed transaction and the available alternatives; and

- finding ways to favorably alter the other side's perceptions (Goldman 1991).

Intercultural negotiation is about effective intercultural communication which is at the heart of successful international negotiation. Intercultural negotiation encompasses all the challenges arising from intracultural communication in addition to the difficulties relating to cultural diversity. Thus, it is worthwhile examining the influence of cultures on negotiation.

\section{Cross-cultural influences on negotiations}

Cultural differences, for example, influence the size of the team directly involved in the negotiation. According to Hofstede's (1991) cross-cultural dimensions, most Western cultures are based on individualism. In contrast, Asian, Middle Eastern and most South American cultures are predicated on the notion of collectivism. In cross-cultural negotiations, this dimension is reflected through the type of individual selected to attend negotiating sessions and to essentially make the decision. Negotiating teams from collectivist society tend to be large. For example, the Japanese as a collectivist culture prefer to use a large contingent of negotiating team. Whereas, for an individualistic culture, such as Americans, it is not unusual to send a single person who could represent them at the negotiating table. In addition, Robbins et al. (2000) research showed that younger negotiators are more common among American teams than in other cultures, and they are more likely to take the final decision. While, a collectivist culture negotiating team, such as an Asian team that respects seniority, is likely to be led by a senior who has high status. He may play a little part in the detailed discussions but has an important 'figurehead' role (Markus and Kitayama 1991). Further, in a collectivist culture, such as Asian, subordinates would brief superiors who in turn use their influence to negotiate and make decisions. Everyone affected by the decision is included in the process (Robbins et al. 2000). Collectivist societies consider people very important. It is difficult for collectivists to separate people from the issues. For the same reason, collectivists are very much reluctant to express disagreement openly. Consequently, non-verbal and indirect communication cues play an important role in negotiation with collectivists. To succeed in business in Korea, for example, a person needs an extraordinary skill to read nunchi which means the look in a person's eyes, the nonverbal reaction of a person to a question (De Mente 1991; Fatehi 1996). As such, an understanding of cultural difference based on individualism/collectivism is essential for a cross-cultural negotiator who may need to incorporate these aspects as part of their overall negotiating strategies. Based on Hofstede's (1991) analysis of cultural dimensions, negotiations between people of masculine and feminine cultures may also present challenges for them to overcome. For the negotiators from masculine societies, ego-preservation is essential. For them, to compromise may give the appearance of giving in, which could be considered a sign of weakness. On the other hand, negotiator from feminine culture may not be aware of the importance of ego for the people of masculine cultures. Building the ego of their counterparts and focusing on the task at hand may help advance negotiations faster (Fatehi 1996). Negotiation is more difficult between the people of different cultures who have different value systems. Negotiators from a high power distance culture may need more information to convince their superiors of the value of the agreement. They may also take a longer time because they have to clear most decisions with those in the position of power. Views on the expected outcomes of the negotiation may also be culturally based. Specifically the expected outcomes of any negotiation may be either integrative or distributive. Integrative outcomes, or win-win situations produce mutual benefits to both the parties. Integrative negotiations result in great benefit for both parties and stable relationship (Bazerman and Neal 1982; Fatehi 1996). Distributive outcomes are the result of competition among the negotiators. Distributive negotiation is a win-lose scenario in which the negotiators believe that they have opposing interest and incompatible alternative choices (Phatak 1997). Americans tend to have a short-term 
distributive way of negotiation, as they are concerned with their own interests and view negotiations competitively, often arriving at distributive outcomes. In contrast, most Asians view negotiation as a long-term relationship and a cooperative task (Lewicki and Litterer 1985). For example, Japanese negotiators emphasize harmonious interdependence and attending to and finding in with others which is indicative of a distributive way of negotiating based on collectivist culture (Lituchy 1997). Bargaining and negotiation are a part of daily life in the Middle East. Foreigners who want to establish business relationships in the Middle East should be ready to combine personal relationship with business transactions (Acuff 1993).

\section{The negotiation process}

Process is the single most important factor predicting the success or failure of a negotiation. An effective process includes managing the negotiation's overall strategy or approach, its stages, and the specific tactics used. As with other aspects of negotiating, process varies markedly across cultures. An effective strategy reflects the situational characteristics and personal backgrounds of the negotiators involved. It balances the position, procedure, timing, and roles of the negotiating partners (Adler 1997). To successfully negotiate globally, Fisher and Ury (1981) advocate for a culturally synergistic approach, based on principled negotiation method, which could lead to fruitful cross-cultural negotiations. This approach involves four steps:

1. Separating the people from the problem;

2. Focusing on interests, not on positions;

3. Insisting on objective criteria (and never yielding to pressure); and

4. Inventing options for mutual gain.

Principled negotiation provides participants for the negotiation with a method of focusing on the basic interests and the mutually advantageous solutions. It enables parties to reach agreement without all haggling and posturing (Fatehi 1996).

\subsection{Stages of negotiation}

There are several basic steps involved in managing the negotiation process. The fist phase typically begins with planning:

\section{Planning}

It starts with negotiators identifying those objectives they would like to attain. Next consideration is given to areas of common ground between the parties. Other major areas include:
- The setting of limits on single point objectives;

- Dividing issues between short term and long term considerations; and

- Determining the sequence in which to discuss various issues (Chaney and Martin 1995).

Meanwhile, Raider advocates that successful negotiators' planning behavior differed from less skilled negotiators in terms of the following criteria:

- Planning time. Successful negotiators use time in ways that are more fruitful to negotiation outcome than average negotiators and this is where successful negotiators tend to pay a lot of attention on how to use available time so as to advantage their negotiations;

- Exploring options. Successful negotiators are inclined to come up with a wide-ranging options than the average negotiators thereby increasing their chances for success;

- Establishing common ground. Unlike the average negotiators, successful negotiators are more focused on developing common ground than paying attention on areas of conflict than of agreement;

- Focusing on long-versus short-term horizons. Successful negotiators are strategically focused and therefore they spend more time on long-term issues than short-term issues. Whereas, the average negotiators do not spend a substantial amount of time on strategic issues;

- Setting limits. Unlike the average negotiators, successful negotiators are focused on developing range objectives thereby providing them with flexibility necessary to succeed in their bargaining;

- Using sequence versus issue planning. In contrast to the average negotiators, successful negotiators discuss each issue under negotiation independently with no preconceived sequence or order of priority during the negotiation process (Raider 1982).

\section{Interpersonal relationship building}

The second phase of the negotiation process involves getting to know the people on the other side. This feeling out period is characterized by the desire to identify those who are reasonable and those who are not. This is particularly important for collectivist culture, as the essence of any negotiation is primarily based on how much there is a trust in interpersonal relationship between partners involved in negotiation.

\section{Exchanging task related information}

In this part of the process, each group sets forth its position on the critical issues. At this point the participants are trying to find out what the other party wants to attain and what it is ready to give up. In negotiating, 
cross-cultural miscommunication can give rise to numerous hurdles for the parties involved. Here is what happened as a result of the Iranians' misinterpretation of a bargaining offer in English.

In Persian, the word compromise apparently lacks the positive meaning it has in English (a midway solution both sides can live with) and has only a negative meaning (her virtue was compromised or our integrity was compromised). Similarly, the word mediator in Persian suggests meddler, someone who is barging in uninvited. In early 1980, United Nations Secretary General Waldheim flew to Iran to deal with the hostage question. His efforts were seriously set back when Iranian national radio and television broadcast in Persian a remark he reportedly made on his arrival in Tehran: I have come as a mediator to work out a compromise. Within an hour of the broadcast, his car was being stoned by angry Iranians.

Source: Fisher and Ury (1981:33)

As can be seen from the foregoing example, a lack of proper understanding of language within its own cultural context can pose a serious hindrance to successful cross-cultural negotiations.

\section{Persuasion}

This is the most important step. The success of the persuasion often depends on:

- How well the parties understand each other's position;

- The ability of each to identify the areas of similarity and differences;

- The ability to create new options; and

- The willingness to work towards a solution.

Goldman propounds that in negotiation what counts is not the reality but the party's perception of reality (Goldman 1991). There are two extreme negotiating positions of hard and soft. Those taking hard positions see every negotiation as a contest of wills. They believe that by taking extreme positions and holding out longer, they will fare better. Often, the other party responds by taking an equally hard position. This exhausts both parties and damages their long-term relationship. On the other hand, soft positions may create a one-sided deal and ill feelings. Avoiding confrontation and taking more accommodating soft position may result in an undue advantage for the other party. Both hard and soft approaches to negotiation are not constructive. The best way would be negotiating on merits or principled negotiations (Fisher and Ury 1981). With this in mind, one also needs to be aware of the negotiation styles across cultures which plays a crucial role in persuasion. For example, Americans push hard for direct answers and fill potential periods of silence with rhetorical embellishments. Latin Americans may simply change the topic when it becomes too pointed or uncomfortable. Chinese negotiators, on the hand, try to avoid conceding any points until the talks near their culmination point. Whereas, the Japanese seem unemotional in their persuasive techniques, but Koreans, Italians, and Middle Eastern negotiators often rely on bravado and intimidation tactics (Holt and Wigginton 2002).

\section{Agreement}

The final phase is the granting of concessions and hammering out a final agreement. To negotiate effectively in the international areas, it is necessary to understand how cultural differences between the parties affect the process. For example, the way Americans negotiate is different from Russians and Asians in that Americans negotiate an issue at a time and then once that issue is resolved, they then move on to focus on the next issue. Whereas, Asians and Russians tend to negotiate a final agreement on everything and few concessions are given until the end (Reardon and Spekman 1994).

\subsection{Cross-cultural dimensions affecting negotiations}

To negotiate effectively, it is important to have a sound understanding of the other side's culture. This includes consideration of areas such as communication pattern, time orientation, and social behaviors (Thompson 1998; Weiss 1994). One negotiation expert recommends the following:

- Do not identify the counterpart's home culture too quickly. Common cues (e.g. name, physical appearance, language, accent, and location) may be unreliable. The counterpart probably belongs to more than one culture.

- Beware of the Western bias toward doing. In Arab, Asian and Latin groups ways of being including feeling, thinking, and talking can shape relationships more powerfully than doing.

- Try to counteract the tendency to formulate simple, consistent, stable images. Not many cultures are simple, consistent or stable.

- Do not assume that all aspects of the culture are equally significant. In Japan, consulting all relevant parties to a decision is more important than presenting a gift.

- Recognize that norm for interactions involving outsiders may differ from those for interactions between compatriots.

- Do not overestimate your familiarity with your counterpart's culture. An American studying Japanese wrote New Year wishes to Japanese contacts in basic Japanese characters but omitted one character. As a result, the message became "Dead man, congratulations" (Weiss 1994). 


\subsection{When to negotiate?}

Given the enormity of global trade, this begs the question, whether one would always need to negotiate in order to successfully conclude a business deal? Based on a unanimous view held by global negotiations experts, negotiation is not always the best approach to doing business. Sometimes the best strategy is 'take it or leave it', other times bargaining, and, on some occasions, negotiations involving problem solving are most appropriate (Raider 1982). Negotiation, compared with bargaining and the take-it-or-leave-it approach, demands more time. Managers should negotiate when the value of the exchange and of the relationship is important; as, for example, within the growing number of global strategic alliances. Negotiating is generally the preferred strategy for creating win-win solutions in the global business environment. Businesspeople should, for example, consider negotiating when any of the following conditions are apparent:

- their power position is low relative to their counterparts;

- the trust level is high;

- the available time is sufficient to explore each party's multiple needs, resources, and options; and

- commitment - not mere compliance - is important to ensure that the agreement is carried out (Adler 1997).

\subsection{Who should negotiate?}

The other party's decisions about their representation at the negotiating table should also affect the composition of the negotiating team. Choices of representation vary. Greek and Latin American top managers may prefer to maintain personal control of all aspects of the process, and so may head the team rather than delegate to a subordinate. The identity of other team is dealt with in terms of number of functions, gender, age and rank (Mead 1998):

Number and functions. A single negotiator faces obvious difficulty if sent up against a team representing the full range of functions in the other organization. The team from China or Japan represents a wide range of constituent groups within the organization. American team often includes a legal representative, which is perceived as hostile and threatening by the Japanese. Gender. A team that includes women may be at an advantage in feminine cultures such as in Scandinavian countries, but not where women are not normally accepted in business, for instance in Arab countries.

Age. An Anglo-company may be mistaken in selecting a young high-flier to head a team negotiating with Chinese or Japanese team. The Asian team is likely to be led by a senior and older person who has a high status as he takes a significant figurehead role.

Rank. The problem of matching team leader is complicated by the far wider currency of the title Vice President in the US than in Japanese organizations. In the USA, the company may have twenty Vice Presidents whereas a Japanese company of equal size has three or four. Moreover, the ranks are not always matching across cultures (Mead 1998).

\subsection{Developing effective negotiation skills}

According to Fisher and Ury (1981), the essence of effective negotiation can be achieved by following these steps:

- Research your opponent: acquire as much information as you can about your opponent's interests and goal for the purpose of understanding opponent's behavior, predicting their responses to your options and to frame solutions;

- Begin with a positive overture;

- Address problems not personalities;

- Pay little attention to initial offers. Treat an initial offer as merely a point of departure as they tend to be extreme and idealistic;

- Emphasize win-win solution if conditions are supportive, look for an integrative solution;

- Be open to accepting third party assistance (Fisher and Ury 1981).

\section{Individual qualities of negotiator}

The role that individual qualities play varies across cultures. Favorable outcomes are most strongly influenced by the negotiator's own characteristics in Brazil, the opponent's characteristics in the USA, the role in Japan and a mixture of negotiators and opponent's characteristics in Taiwan (Graham 1983). Specifically, Brazilian negotiators achieve higher profits when they act more deceptively and in their own self-interest. American negotiators do better when their counterparts are honest, not self-interested and introverted. In Taiwan negotiators do better when they act deceptively and when their counterparts are neither self-interested nor have particularly attractive personalities. The key individual characteristics of negotiators for these four countries are given in the following Table 1.

\section{Different approaches to negotiation}

There are essentially two general approaches to negotiation, and they include distributive bargaining and integrative bargaining. Distributive bargaining refers to the negotiations that seek to divide up a fixed amount of resources and is a win-lose solution. When engaged 
Table 1. Key Individual characteristics of negotiators in different countries

\begin{tabular}{|c|c|c|c|}
\hline $\begin{array}{l}\text { American } \\
\text { negotiator }\end{array}$ & $\begin{array}{l}\text { Japanese } \\
\text { negotiator }\end{array}$ & $\begin{array}{c}\text { Chinese } \\
\text { (Taiwan) } \\
\text { negotiator }\end{array}$ & $\begin{array}{l}\text { Brazilian } \\
\text { negotiator }\end{array}$ \\
\hline $\begin{array}{l}\text { Preparation and } \\
\text { planning skills }\end{array}$ & Dedication to job & $\begin{array}{l}\text { Persistence and } \\
\text { determination }\end{array}$ & $\begin{array}{l}\text { Preparation and planning } \\
\text { skills }\end{array}$ \\
\hline Thinking under pressure & Perceive and exploit power & Win respect and confidence & Thinking under pressure \\
\hline Judgement and Intelligence & Win respect and confidence & $\begin{array}{l}\text { Preparation and planning } \\
\text { skills }\end{array}$ & Judgement and intelligence \\
\hline Verbal expressiveness & Integrity & Product knowledge & Verbal expressiveness \\
\hline Product expertise & Demonstrate listening skills & Interesting & Product expertise \\
\hline Perceive and exploit power & Broad perspective & Judgement and Intelligence & Perceive and exploit power \\
\hline Integrity & Verbal expressiveness & & Competitiveness \\
\hline
\end{tabular}

Source: Graham (1983) as adapted by Adler (1997)

in distributive bargaining, the negotiator should focus on trying to get the opponent to agree to his specific target point or to get as close to it as possible (Robbins et al. 2000). This style of negotiation is most common amongst Americans. In the same vein, Kuhn (1988:27) a negotiation expert, advises American negotiators: Don't worry what others get. Don't worry what others think. Just know what you want to accomplish. Keep your eye on the ball and don't allow extraneous pressures to distract you. A good deal maker is constantly enhancing his or her perceived power. The trick is track record. Everyone wants to associate with a winner. In contrast to distributive bargaining, integrative bargaining operates under the assumption that there is at least one settlement that results in win-win situation for the parties involved in the negotiation. This is indicative of Japanese, Chinese, South Americans which is based on collectivist culture. In general, integrative bargaining is preferable to distribute bargaining as it builds longterm relationship and facilitates working together in the future. It bonds the negotiators and allows them to leave the bargaining table feeling that they have both achieved victory. Such an integrative strategy is recommended for cross-cultural negotiations. Table 2 provides a comparison between integrative bargaining versus distributive bargaining strategies.

\section{Negotiation strategies: some guidelines}

Acuff (1993) suggests the following ten negotiation strategies that will work anywhere in the world:

- Plan the negotiation;

- Adopt a win-win approach;

- Maintain high aspirations;

- Use language that is simple and accessible;

- Ask a lot of questions then listen with your eyes and ears;

- Build solid relationship;

- Maintain personal integrity;

- Conserve concessions;

- Be patient;

- Be culturally literate and adopt the negotiating strategies of the host country environment.

Table 2. Distributive bargaining versus integrative bargaining

\begin{tabular}{lll}
\hline \multicolumn{1}{c}{$\begin{array}{c}\text { Bargaining } \\
\text { characteristics }\end{array}$} & \multicolumn{1}{c}{ Distributive bargaining } & \multicolumn{1}{c}{ Integrative bargaining } \\
\hline Available Resources & Fixed amount of resources to be divided & Variable amount of resources to be divided \\
\hline Primary Motivation & I win, you lose & I win, you win \\
\hline Primary Interest & Opposed to each other & Compatible with each other \\
\hline Focus of relationship & Short-term view & Long-term view \\
\hline
\end{tabular}

Source: adapted from Lewicki and Litterer (1985) 
On the other hand, Kirkbride and Tang (1995) have argued that for any negotiator to succeed in their negotiations, they need to observe the following rules:

- Always set explicit limits or ranges for the negotiation process;

- Always seek to establish general principles early in the negotiation;

- Always focus on potential areas of agreement and seek to expand them;

- Avoid taking the negotiation issues in sequence;

- Avoid excessive hostility, confrontation and emotion;

- Always give the other party something to take home; and

- Always prepare to negotiate as a team.

\subsection{Negotiation tactics}

Negotiation includes verbal, non-verbal, and situational tactics. Prevalence of these tactics is at variance across cultures. Individualist cultures representing Australians and Americans would consider verbal tactics to be most important, whereas people from collectivist cultures, such as Asians would prefer non-verbal tactics during their cross-cultural negotiations. A brief discussion of negotiation tactics is merited here.

\section{Verbal tactics}

Negotiators use many verbal tactics. Some of the more common tactics used in negotiations include promises, threats, recommendations, warnings, rewards, punishments, normative appeals, commitments, self- disclosure, questions and commands. The use and meaning of many of these tactics vary across cultures. Research shows that the profits of a negotiator increase when they make high initial offer, ask a lot of questions, and do not make many verbal commitments until the end of the negotiating process. In short, verbal behavior is critical to the success of negotiations (Hodgetts and Luthans 2000).

\section{Non-verbal tactics}

Non-verbal behavior represents communication other than verbal. It includes how the negotiators express the words rather than the words themselves. Non-verbal behavior subsumes tone of voice, facial expressions, body distance, dress, gestures, timings, silences and symbols. Non-verbal behavior conveys multiple messages, many of them are responded to at a subconscious level. Negotiators frequently respond more emotionally and powerfully to the non-verbal than the verbal message. As with verbal behavior, non-verbal behavior also differs considerably across cultures. For example, Japanese use the most silence, Americans a moderate amount, and Brazilians almost none at all.
Americans often respond to silence by assuming that the other team disagrees or has not accepted their offer. Moreover, they tend to argue and make concessions in response to silence. This response does not cause problems in negotiating with Brazilians, but it severely disadvantages Americans when they are dealing with Japanese. While the Japanese silently consider the Americans' offer, the Americans interpret the silence as rejection and respond by making concessions (e.g., by lowering the price) (Adler 1997).

\section{Situational tactics}

Another set of tactics generally used could be classified as situational tactics, which include location; time limit; and physical arrangement.

\section{Location}

Where should negotiation be held is a significant consideration in terms of a successful negotiation. Most negotiators select neutral locations for various forms of negotiations. Business entertainment has become a main feature of neutral location, used by the negotiating team primarily to become acquainted with members of the opposing team. Japanese business people spend almost $2 \%$ of their GNP on entertaining clients -even more than they spend on national defence $(1.5 \%)$ (Adler 1997). However, using a neutral site results in a number of benefits like each party having a limited access to its home office for receiving a great deal of negotiating information and advice for gaining an advantage over the other. Secondly, cost of staying at the site often is quite high, so both sides have an incentive to conclude negotiations quickly (Hodgetts and Luthans 2000).

\section{Time limit}

It is an important negotiation tactic when one party is under time constraint. The duration of a negotiation can vary markedly across cultures. Americans, being particularly impatient, often expect negotiations to take a minimum amount of time.

During the Paris Peace Talks, designed to negotiate an end
to the Vietnam War, the American team arrived in Paris
and made hotel reservations for a week. Their Vietnamese
counterparts leased a chateau for a year. As the negotia-
tions proceeded, the frustrated Americans were forced to
continually renew their weekly reservations to accommo-
date the more measured pace of the Vietnamese.

Source: Adler (1997: 200)

Concessions in negotiations are usually made towards the time deadline of the party making the concession. This obviously puts time-conscious cultures, such as Americans, at a disadvantage (Jackson 1993). 


\section{Physical Arrangements}

Sitting around a boardroom table at opposite sides emphasizes a confrontation situation. Sitting at right angle and facing the problem to solve rather than other party engenders Co-operation. In America the negotiating parties sit opposite each other. Whereas in Japan, the negotiating parties sit at right angles and face the problem together (Adler 1997). For example, the physical arrangement, as shown by Japanese is indicative of their emphasis on harmony in their approach to negotiation which is based on their collectivist culture.

\section{Concluding remarks}

In this research article, the definition of negotiation was provided along with conceptualizations of negotiations across cultures. Further it was argued that negotiations could be classified into intracultural and intercultural. To negotiate a business deal, international managers need to recognize the cultural differences in communication and negotiation styles. Accordingly, the skills need to be developed and appropriate strategies and tactics are to be used. Some cultures view negotiation as a competitive game, whereas some other cultures view negotiations as a relationship building exercise. Such different views call for different types of negotiations and different skills.

Finally, international managers would greatly benefit by developing high-level intercultural communication competence, a key contributing factor to successful international negotiations.

\section{References}

Acuff, F. L. 1993. How to negotiate anything with anyone anywhere around the world. New York: American Management Association.

Adler, N. 1997. International dimensions of organizational behavior. $3^{\text {rd }}$ ed. Cincinnati, OH: South-Western College Publishing.

Adler, N. J.; Graham, J. L. 1989. Cross-cultural interaction: The international comparison fallacy, Journal of International Studies 20(3): 515-537.

Bazerman, M. H.; Neal, M. A. 1982. Improving negotiations effectiveness: Under final offer arbitration: the role of selection and training, Journal of Applied Psychology 67: 543-554.

Casse, P. 1981. Training for the cross-cultural mind. $2^{\text {nd }}$ ed. Washington, DC: Society for Intercultural Education, Training and Research.

Chaney, L. H. and Martin, S. J. 1995. International business communication. Englewood Cliffs, NJ: Prentice Hall.
De Mente, B. 1991. Japanese etiquette and ethics in business. Lincolnwood, IL: NTC Business Books.

Fatehi, K. 1996. International management: A cross culture and functional perspective. Upper Saddle River, NJ: Prentice Hall.

Fisher, R. and Ury, W. 1981. Getting to Yes. New York: Penguin books.

George, J. M.; Jones, G. R.; Gonzalez, J. A. 1998. The role of affect in cross-cultural negotiations, Journal of International Business Studies 29: 749-72.

Goldman, A. L. 1991. Setting for more. Washington, DC: The Bureau of National Affairs.

Graham, J. 1983. Brazilian, Japanese and American business negotiations, Journal of International Business Studies 14(1): 47-56.

Gulbro, R. and Herbig, P. 1995. Differences in cross-cultural negotiation behavior between manufacturers and serviceoriented firms, Journal of Professional Services Marketing 13: 23-29.

Hofstede, G. 1991. Cultures and organizations: Software of the mind: Intercultural cooperation and its importance for survival. New York: McGraw-Hill.

Hodgetts, R. M. and Luthans, F. 2000. International management. New York: Mc Graw Hill Inc.

Holt, D. H. and Wigginton, K. W. 2002. International management. $2^{\text {nd }}$ ed. Orlando, FL: Harcourt, Inc.

Jackson, T. 1993. Organizational behavior in international management. London: Butterworth Heinemann.

Kirkbride, P. S. and Tang, S. F. Y. 1995. Negotiations: Lessons from behind the bamboo curtain, in Jackson, T. (eds.). Cross Cultural Management. Oxford: Butterworth - Heinemann, 293-304.

Kuhn, R. L. 1988. Dealmaker: all the negotiating skills and secrets you need. New York: John Wiley and Sons.

Lewicki, R. J. and Litterer, J. A. 1985. Negotiations. Homewood, IL: Irwin.

Lituchy, T. R. 1997. Negotiations between Japanese and Americans: The effects of Collectivism on Integrative Outcomes, Canadian Journal of Administration Sciences 14(4): 386-395

Markus, H. R. and Kitayama, S. 1991. Culture and the selfimplications for cognition, emotion and motivation, Psychological Review 98: 224-253.

Mead, R. 1998. International management: Cross-cultural dimensions. Cambridge, USA: Blackwell Publishers.

Perlmutter, H. V. and Heenan, D. A. 1974. How multinational should your top manager be? Harvard Business Review 52: 121-132.

Phatak, A. V. 1997. International management: Concepts and cases. Cincinnati, OH: South-Western College Publishing. 
Raider, E. 1982. International negotiations: A training program for corporate executives and diplomats. New York: Ellen Raider International Inc.

Reardon, K. K. and Spekman, R. E. 1994. Starting out right: Negotiating lessons for domestic and cultural business alliances, Business Horizons 37(1): 71-79.

Robbins, S.; Bergman, R.; Stagg, I. 2000. Management. $2^{\text {nd }}$ ed. Prentice Hall Publishing.

Saee, J. 2005. Managing organizations in a global economy. Mason, $\mathrm{OH}$ : South Western -Thomson Learning.
Thompson, L. 1998. The mind and heart of the negotiator. Upper Saddle River: NJ: Prentice Hall.

Weiss, S. E. 1994. Negotiating with Romans - Part 1, Sloan Management Review 35(2): 51-61.

Weiss, S. E. 2006. International business negotiation in a globalizing world: Reflections on the contributions and future of a (sub) field, International Negotiation 11: 287-316. 